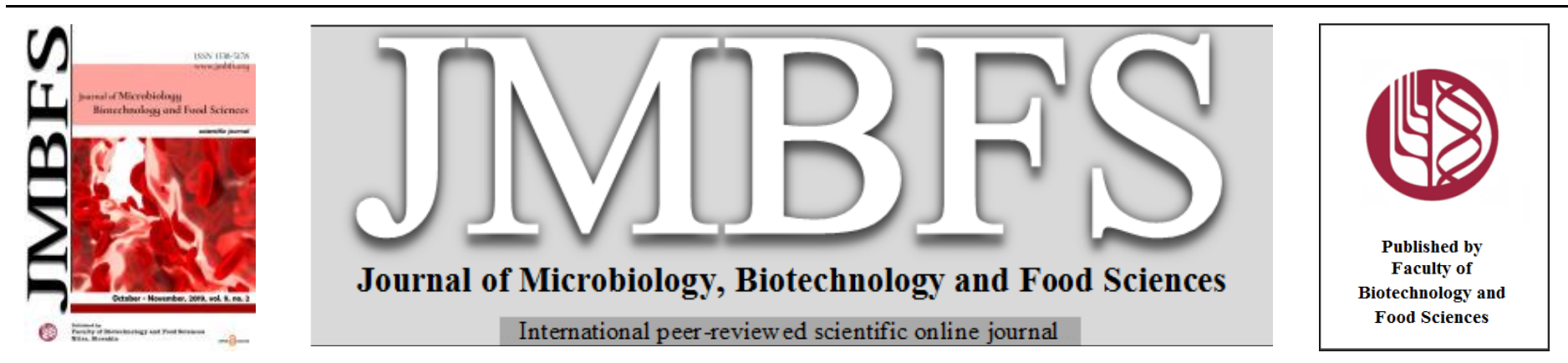

\title{
INVESTIGATION OF FERMENTATION CONDITION FOR PRODUCTION ENHANCEMENT OF POLYHYDROXYALKANOATE FROM CHEESE WHEY BY PSEUDOMONAS SP.
}

\author{
Sathya A Bose ${ }^{1}$, Sivashankar Raja ${ }^{4}$, Kanimozhi Jeyaram ${ }^{3}$, Santhiagu Arockiasamy ${ }^{2}$, Sivasubramanian Velmurugan ${ }^{1 *}$
}

Address(es): Sivasubramanian V,

${ }^{1}$ Department of Chemical Engineering, National Institute of Technology Calicut, Kerala, India.

${ }^{2}$ School of Biotechnology, National Institute of Technology Calicut, Kerala, India.

${ }^{3}$ Departement of Biotechnology, Kalasalingam Academy of Research and Education, Tamiadu, India.

${ }^{4}$ Department of Chemical Engineering, Hindustan Institute of Technology and Science, Tamilnadu, India.

*Corresponding author: siva@nitc.ac.in

doi: $10.15414 / j m b f s .2020 .9 .5 .890-898$

ARTICLE INFO

Received 5. 6. 2018

Revised 19. 10. 2019

Accepted 22. 10. 2019

Published 1. 4. 2020

Regular article

open $\odot$ access

\begin{abstract}
A newly acquired polyhydroxyalkanoate (PHA) producing Pseudomonas $s p$. was characterized based on 16S rRNA gene sequences (1,423 bp) and identified as P. Putida SS9. This strain P. putida SS9 was considered in respect of its potential for achieving maximum production of PHA under controlled volumetric oxygen transfer coefficient $\left(\mathrm{k}_{\mathrm{L}} \mathrm{a}\right)$ using inexpensive substrate, cheese whey. The significant parameters such as $\mathrm{pH}$, temperature, nitrogen source concentration were studied in shake flask. The influence of aeration and agitation on $\mathrm{k}_{\mathrm{L}} \mathrm{a}$ and production of PHA was studied in stirred tank fermenter. Maximum PHA concentration of 5.98 and $4.33 \mathrm{~g} / \mathrm{l}$ was obtained using cheese whey medium (CWM) and mineral salts medium (MSM) respectively. Further, the properties of PHA were analyzed by Differential scanning calorimetry, Thermal gravimetry analysis. The structure of the compound was elucidated by Fourier transform infrared and Nuclear magnetic resonance spectroscopy. The findings suggested that the cheese whey could be a most excellent alternative carbon source for PHA production using P. putida SS9 and thus it could effectively replace the synthetic mineral salts medium under optimum $\mathrm{k}_{\mathrm{L}} \mathrm{a}$. The nucleotide sequence proclaimed in this work will emerge in the GenBank nucleotide sequence database under accession number MF403057.
\end{abstract}

Keywords: Pseudomonas putida SS9; Polyhydroxyalkanoate; Volumetric oxygen transfer coefficient

\section{INTRODUCTION}

Most of the synthetic polymers produced from petrochemical resources are not biodegradable and are generating serious environmental problems. Million tons of these non-degradable plastics accumulate in the environment in a year (Bhuwal et al., 2013). Incineration of plastic wastes releases toxic emissions into the environment. As the fossil fuels are also becoming expensive, alternate resources are essential (Averous and Pollet, 2012). These facts stimulated the production of biodegradable polymers due to both ecological and environmental concerns. These are polyesters of different hydroxyalkanoate synthesized by various microorganisms from renewable resources which are biodegradable and nontoxic (Khandpur et al., 2012). Biopolymers are made partly or wholly from biological sources or living organisms. Polyhydroxyalkanoates (PHA) are the macromolecule polyester naturally synthesized by several microbial species and is being contemplated as an alternate for conventional plastics. The conventional fossil fuel derived plastics require several decades to degrade, but PHA can be absolutely degraded within months by using microbial diversity (Kumar et al., 2004). Several bacteria accumulate PHA spontaneously as energy source when the bacterial growth is limited by depletion of nutrients such as nitrogen or phosphorous in the presence of excess amount of carbon (Kedia et al., 2014). It has been reported that the nitrogen source concentration in the media highly influences the production of PHA (Khandpur et al., 2012). The production cost is comparatively higher and is the major drawback in the commercialization of biodegradable polymers. Many researchers have reported that approximately $50 \%$ of the overall production cost is only due to carbon source. Therefore, inexpensive sources such as renewable sources, agro-industrial raw materials, and food processing byproducts could be best alternatives to reduce the production cost (Tanamool et al., 2013). Cheese whey, a by-product of the dairy industry was believed to be immaterial for years and was either used as an animal feed or it was disposed of as waste. Recognizing that over 160 million tons of whey is generated across the globe annually (Geiger et al., 2016), brings about the need for new techniques in utilizing whey, which might increase its value. A few investigations in the past recent years were conveyed out concerning the vitality of whey, its nutritional value and the properties of its ingredients (Macwan et al., 2016). Further, its disposal possesses environmental pollution in the surrounding where the cheese whey is discharged. The presence of high lactose content in the discharge leads to very high BOD of $30,000-50,000 \mathrm{mg} / \mathrm{l}$ and chemical oxygen demand of $60,000-80,000 \mathrm{mg} / \mathrm{l}$, which is responsible for environmental pollution. Discarding of whey also constitute a considerable loss of potential nutrients and energy and has been looked upon seriously by the environmentalists and technologists due to its potent polluting strength (Macwan et al., 2016; Koller et al., 2012). In India, 2 million tons of whey, containing about $1,30,000$ tons of valuable milk nutrients are produced per annum (Goyal and Ghandhi, 2009). Cheese whey is rich in fermentable nutrients such as lactose, lipids, soluble proteins and also contains citric acid, non-protein nitrogen compounds (urea and uric acid) and B group vitamins (Siso, 1996). Due to these reasons, cheese whey signified as an assuring substrate for cheap production of PHA in large amounts. Polyhydroxybutyrate (PHB) is the extensively studied PHA. PHB has been widely used to produce bottles, fibers, films for biodegradable packaging materials. On the other hand, PHB is found to have application in medicinal field such as bone plates, tacks, surgical sutures, rivets and several other materials (Lopez et al., 2012). Aeration and agitation are considered as important parameter to offer optimum oxygen transfer rate throughout aerobic fermentation processes. Oxygen mass transfer can be investigated by assessing the volumetric mass transfer coefficient, $\mathrm{k}_{\mathrm{L}} \mathrm{a}$. Therefore, determination of $\mathrm{k}_{\mathrm{L}} \mathrm{a}$ in a fermenter is necessary to demonstrate its aeration efficiency and to compute the influences of operating variables on oxygen supply. Oxygen transfer in aerobic processes is imperative and the oxygen deficiency greatly influences the process performance. As a result, oxygen mass transfer becomes most critical phenomenon in the design and performance of fermenter (Moutafchieva et al., 2013). Nutrient transfer and the distribution of air and oxygen can be controlled by agitation, whereas the oxygenation of the culture is determined by aeration. Aeration also contributes to bulk mixing of the fermentation fluid, especially where mechanical agitation speeds are low. Agitation together with aeration plays an important role in overall oxygen transfer (Bajaj and Singhal, 2010). 
Here, an attempt was made to produce and characterize PHA from new strain Pseudomonas putida SS9 using cheese whey as substrate. This may be the excellent solution of an industrial waste clearance problem and that can be combined with improved cost effectiveness in the production of biodegradable polymers. Bacterial growth was monitored and the effect of nitrogen concentration was studied. The produced PHA was characterized using Differential scanning calorimetry (DSC), Thermal gravimetry analysis (TGA), Fourier transform infrared spectroscopy (FTIR) and Nuclear magnetic resonance (NMR)

\section{MATERIALS AND METHODS}

\section{Materials}

All the chemicals utilized for the preparation of synthetic media were procured from Hi- Media, India. Chemicals and solvents employed for analysis were analytical grade reagents obtained from Merck, India.

\section{Microorganism and growth conditions}

P. putida SS9 was isolated from food processing wastewater collected from dairy industry (Kerala Co-operative milk marketing Federation or MILMA) in Kozhikode, India. The strain was isolated using nutrient agar medium containing cetrimide, fucidin and cephalotin. The presence of PHAs was evidenced by staining the biopolymer inside the cells with Nile blue sulphate as described by Kitamura and Doi, (1994). The colonies stained with nile blue were irradiated with a short wavelength of $254 \mathrm{~nm}$ in UV illuminator. The colonies with PHA were found fluoresced bright orange. The inoculum was aseptically prepared in a test tube containing nutrient broth medium by incubating it at ambient temperature in a rotary shaker for $24 \mathrm{~h}$ at $200 \mathrm{rpm}$. The seed culture was transferred to $100 \mathrm{ml}$ of nutrient broth and growth pattern was observed at regular intervals by recording the absorbance at $600 \mathrm{~nm}$ in UV-Vis Spectrophotometer (Gumel et al., 2014). The culture was maintained on nutrient agar slant and refrigerated at $4^{\circ} \mathrm{C}$. Then it was sub cultured at intervals of six months for further use.

\section{Identification of isolate by $16 \mathrm{~S}$ rRNA gene}

The genomic DNA from the isolate was extracted, as per standard protocol described earlier (Sambrook et al., 1989; Wei et al., 2011). The 16S rRNA gene amplification was carried out with Taq polymerase using forward primer: $8 \mathrm{~F}\left(5^{\prime}\right.$ AGAGTTTGATCCTGGCTCAG-3') and reverse primer 1541R (5'AAGGAGGTGATCCAGCCGCA-3') and commercially analyzed by Yaazh genomics, Tamilnadu, India. The 27F/1492R primers were used for sequencing the PCR product. Sequencing reactions were carried out using an ABI PRISM Big DyeTM Terminator Cycle Sequencing Kits with AmpliTaq DNA polymerase (FS enzyme) (Applied Biosystems). Contigs having query length $1423 \mathrm{bp}$ were analyzed to identify the sequence similarities using NCBI BLAST (Nationa Centre for Biotechnology Information http://www.ncbi.nml.nih.gov) program, compared to the GenBank nucleotide database and identified using the EzTaxon program. Sequences of newly characterized $P$. putida SS9 were deposited at the GenBank database under the accession number: MF403057.

\section{Production medium}

The organism was cultivated in mineral salts medium (MSM) as reported by Bertrand et al., (1990). The bacterial culture was simulated under nitrogen starvation condition to bring out the intracellular PHA from the cells (Nigam et al., 2011). Biosynthesis of PHA was studied by means of two step batch culture. In the first step, the cells were cultured under nutrient balanced MSM at $30^{\circ} \mathrm{C}$ and agitated at $200 \mathrm{rpm}$ till it reached exponential phase. In the second step, the cells were transferred to nitrogen deficient MSM to enhance the production of PHA. The primary concentration of nitrogen source in the medium was $2 \mathrm{~g} / \mathrm{l}$ of ammonium sulphate $\left(\left(\mathrm{NH}_{4}\right)_{2} \mathrm{SO}_{4}\right)$. Bacterial growth and PHA content was determined at different levels of nitrogen source $(0.5,1.0,1.5,2.0 \mathrm{~g} / 1$ of $\left.\left(\mathrm{NH}_{4}\right)_{2} \mathrm{SO}_{4}\right)$

\section{Analytical methods}

\section{Cell growth analysis}

Cell growth was analyzed using biomass concentration. Bacterial cells were harvested using centrifugation at $9000 \mathrm{rpm}, 4^{\circ} \mathrm{C}$ for $10 \mathrm{~min}$. The supernatant was decanted and the pellets were freeze dried. After drying, dry cell weight (DCW) of the sample was gravimetrically determined. The conversion factor was constituted by plotting $\mathrm{OD}_{600}$ versus DCW. Samples were diluted by appropriate ratios to ensure that the measured $\mathrm{OD}_{600}$ were in the range $0.2-0.9$. The resulting cell pellet was lyophilized and preserved for further extraction. Residual biomass was estimated as the difference between dry cell weight and dry weight of extracted PHA (eqn. 1) (Bhuwal et al., 2013).
Biomass residue $(g / l)=D C W(g / l)-$ Dry weight of extracted PHA $(g / l)$

\section{Extraction of PHA}

PHA extraction was performed using the dispersion method of sodium hypochlorite and chloroform (Singh and Parmar, 2011). Bacterial cells were collected by centrifuging at $15000 \mathrm{rpm}$ for $15 \mathrm{~min}$ at ambient temperature followed by washing with deionized water and then with phosphate buffered saline (PBS). The cell pellets were separated from supernatant and air dried for $20 \mathrm{~min}$ and the DCW was determined. Chloroform and 6\% sodium hypochlorite were added to cell pellets at the ratio of $12.5 \mu \mathrm{l}: 12.5 \mu \mathrm{l}(\mathrm{v} / \mathrm{v})$. The mixture was incubated at $30^{\circ} \mathrm{C}$ for $12 \mathrm{~h}$. After incubation, the dispersion was centrifuged at $10000 \mathrm{rpm}$ for $10 \mathrm{~min}$ at ambient temperature. This centrifugation results in three phase solution, with the bottom phases of chloroform containing PHA. The chloroform layer was carefully transferred to a new ampoule and its volume was measured. A mixture of methanol and water in the ratio of 7:3 (v/v) were added 5 times to the volume of chloroform solution to obtain precipitate. Further the precipitation was enhanced by centrifuging at $15000 \mathrm{rpm}$ for $15 \mathrm{~min}$ at ambient temperature. The pellets were separated from supernatant and $0.1 \mathrm{ml}$ of concentrated $\mathrm{H}_{2} \mathrm{SO}_{4}$ was added to it. The mixture was then boiled for $20 \mathrm{~min}$ at $100{ }^{\circ} \mathrm{C}$ and cooled. The absorbance was noted to quantify the content of PHA in the mixture. The standard calibration curve was prepared by using crotonic acid and the sample concentrations were adopted from this standard calibration chart.

\section{Determination of PHA content}

The standard curve of crotonic acid was prepared with known concentrations. The amount of PHA per gram DCW of bacterial cells was determined from the standard graph of crotonic acid. The percentage of intracellular PHA accumulation is estimated as the percentage composition of PHA in the dry cell weight as described in eqn. (2)

$$
\text { PHAcontent }(\%)=\frac{\text { PHA concentration }(g / l)}{D C W(g / l)} \times 100
$$

The extracted PHA was converted to crotonic acid by adding $98 \% \mathrm{H}_{2} \mathrm{SO}_{4}$ and heating to $60{ }^{\circ} \mathrm{C}$ for $1 \mathrm{~h}$. Maximum absorption for crotonic acid was observed at $235 \mathrm{~nm}$. The absorbance of the solution was measured in UV-Visible spectrophotometer at $235 \mathrm{~nm}$ against $\mathrm{H}_{2} \mathrm{SO}_{4}$ as blank. The quantity of PHB per gram DCW of $P$. putida SS9 was determined using standard curve of crotonic acid (Nair et al., 2008).

\section{Effect of parameters}

The influencing parameters such as temperature, $\mathrm{pH}$, and nitrogen source concentration were studied by one variable at a time (OVAT) experimental design, i.e., the selected parameter is varied while keeping all other parameters fixed. The effects of temperature $\left(25,30,35\right.$ and $\left.40{ }^{\circ} \mathrm{C}\right), \mathrm{pH}(6,7,8$ and 9$)$ and nitrogen source concentration $\left(0.5,1.0,1.5\right.$ and $2.0 \mathrm{mg} / \mathrm{l}$ of $\left.\left(\mathrm{NH}_{4}\right)_{2} \mathrm{SO}_{4}\right)$ on DCW, PHA concentration, PHA yield were investigated. Experiments for the batch fermentation was executed in a $500 \mathrm{ml}$ shake flask with $100 \mathrm{ml}$ of culture medium. Components of the culture medium and production conditions were varied in consonance with experimental design. The results of shake flask studies were executed by concordance of three experimental runs for all the selected parameters.

\section{PHA production using cheese whey as substrate}

Cheese whey, collected from (Kerala Co-operative milk marketing Federation or MILMA), Kozhikode, India was used to cultivate the $P$. putida SS9. Cheese whey was boiled for 5-10 min at $95-100{ }^{\circ} \mathrm{C}$ and cooled to room temperature. The solution was filtered and the $\mathrm{pH}$ was adjusted to 7 with $1 \mathrm{M} \mathrm{H}_{2} \mathrm{SO}_{4}$. Cheese whey was then added to contents of MSM excluding carbon source and sterilized by autoclaving at $15 \mathrm{lb}$ and $121^{\circ} \mathrm{C}$ for 20 minutes. The organism was allowed to grow in the medium with cheese whey as carbon source. After $72 \mathrm{~h}$ of incubation, extraction of PHA was done as described above and the amount of PHA produced was estimated (Yellore and Desai, 1998).

\section{Nitrogen and carbon estimation}

Since the nitrogen content in the CWM was unknown, it is essential to calculate the amount of organic nitrogen present and utilized in the CWM. Therefore, organic nitrogen in the sample left after the production of PHA was analyzed in the ammonia test using distillation process. The excess sample was digested and the converted ammonia was distilled for analysis. The amount of nitrogen in a sample can be calculated from the quantified amount of ammonia ions by 
distillation procedure as mentioned in standard protocol of American Public Health Association (APHA) (Eugene et al., 2012). The concentration of ammonia nitrogen can be calculated from eqn. (3)

Ammonia Nitrogen $(m g / l)=\frac{((A-B) \times 280)}{\text { sample }(m l)}$

Where $\mathrm{A}=$ Volume of sulfuric acid titrated for sample $(\mathrm{ml})$ and $\mathrm{B}=$ Volume of sulfuric acid titrated for blank (ml).

Similarly, the initial carbon source concentration in cheese whey was estimated in terms of lactose by Lane- Eynon method as per IS: SP: 18, Part XII (1981) (Kumar et al., 2014).

Carbon present $=F \times V \times \frac{100}{T \times 1000 \times w}$

Where $F=$ Corrected factor, $T=$ Titre, $V=$ Volume to which solution is made up in the volumetric flask and $w=$ weight of volume of cheese whey taken for the determination.

\section{Reactor studies}

All the experiments were performed in a $3 \mathrm{~L}$ fermenter (Newbrunswick BIOFLO 110 model). Sterile air was sparged in a controlled flow through ring sparger with rotameter, filter and dissolved oxygen measurement were recorded as DO\% using polarographic DO probe. Agitation was offered with fixed blade impeller and the rate was controlled through electromagnetic impulse. A $5 \%(\mathrm{v} / \mathrm{v})$ of inoculum was inoculated in to the production medium and the fermentation was carried out at optimum $\mathrm{pH}$ and temperature.

\section{Effect of aeration and agitation rates on biopolymer production}

The $P$. putida SS9 was cultivated in a $3 \mathrm{~L}$ fermenter containing $2 \mathrm{~L}$ medium for biopolymer production at $30{ }^{\circ} \mathrm{C}$ with controlled $\mathrm{pH}$ at 7.0 (using $0.1 \mathrm{~N} \mathrm{NaOH}$ ) with varying aeration $(0.5,0.75,1.0,1.25$ and $1.5 \mathrm{vvm})$ and agitation rates $(100$ 200, 300, and $400 \mathrm{rpm})$. Samples were harvested at regular interval for determination of DCW, DO \%, and PHA yield.

\section{Effect of aeration and agitation rates on OUR, OTR, and $k_{L} a$ values}

Oxygen uptake rate (OUR), oxygen transfer rate (OTR) and $\mathrm{k}_{\mathrm{L}} \mathrm{a}$ in the fermenter were determined during cultivation by dynamic gassing out method reported by Garcia-Ochoa et al., (2000). The mass balance equation for dissolved oxygen (DO) in batch fermentation system can be expressed as,

$\frac{d C_{0}}{d t}=O T R-O U R=k_{L} a \cdot\left(C_{L}^{*}-C_{L}\right)-Q_{o_{2}} \cdot C_{x}$

where $k_{L} a\left(C_{L}{ }^{*}-C_{L}\right)$ and $\left(Q o_{2} . C_{x}\right)$ are the volumetric $O T R$ and $O U R$, respectively. To determine OUR, the aeration into the system was interrupted (OTR $=0$ ), the value of $\mathrm{DO} \%$ drop off as a result of cellular respiration and the slope of graph (DO\% versus time) gives OUR.

$\frac{d C_{0}}{d t}=O U R=-Q_{o_{2}} \cdot C_{x}$

To determine OTR, the aeration was restarted and this lead to the increase of DO\% and OTR value. The OTR can be determined according to eqn. (7),

$O T R=\frac{d C_{0}}{d t}+O U R$

To determine $\mathrm{k}_{\mathrm{L}} \mathrm{a}$, eqn. (5) could be integrated at which the aeration commenced $\left(t=t_{1}\right.$, so $\left.\mathrm{Co}_{2}=C_{I}\right)$ and another time $\left(t=t_{2}\right.$, so $\left.\mathrm{Co}_{2}=C_{2}\right)$, resulting in eqn. (8),

$\left(Q_{o_{2}} \cdot C_{x}\right)\left(t_{2}-t_{1}\right)+\left(C_{2}-C_{1}\right)=k_{L} a \cdot \int\left(C_{L}^{*}-C_{L}\right) d t$

The $\mathrm{k}_{\mathrm{L}} \mathrm{a}$ values were estimated by solving equation (8) using the integration algorithms considered for experiments (Bandaiphet and Prasertsan, 2006; Tribe et al., 1995). The $\mathrm{k}_{\mathrm{L}}$ a values were analyzed for different aeration $(0.5,0.75,1.0$ 1.25 , and $1.5 \mathrm{vvm})$ and agitation rate $(\mathrm{N})(100,200,300$, and $400 \mathrm{rpm})$ in both MSM and CWM. Critical DO level of about $15 \%$ saturation air before re-aeration was maintained to avoid the lethal effect due to deficiency of oxygen in microbial activity.

\section{Characterization of PHA}

\section{Fourier transform infrared spectroscopy}

The functional group of PHA extracted from the organism P. putida SS9 was investigated by FTIR spectroscopy. Analysis was performed in the spectral range of $4000-400 \mathrm{~cm}^{-1}$ to validate the functional groups of the extracted biopolymer.

\section{Nuclear magnetic resonance spectroscopy}

NMR analysis was performed to investigate the quality of PHB structura composition. The ${ }^{1} \mathrm{H}$ and ${ }^{13} \mathrm{C}$ NMR spectrum was obtained for samples using deuterated chloroform $\left(\mathrm{CDCL}_{3}\right)$ as solvent.

\section{Differential scanning calorimetry}

DSC was used to distinguish the melting temperature $\left(T_{m}\right)$ and glass transition temperature $\left(T_{g}\right)$ of sample. The study was performed by varying the temperature range from -50 to $250{ }^{\circ} \mathrm{C}$ at a heating and cooling rate of $10^{\circ} \mathrm{C}$ and $5{ }^{\circ} \mathrm{C} \mathrm{min}$ respectively. The polymer crystallinity $\left(X_{p}\right)$ of the biopolymer was computed from the endothermic melting enthalpy $\left(\Delta H_{m}\right)$ on the basis of melting enthalpy $\left(\Delta H_{m}^{\circ}\right)$ of $100 \%$ crystalline poly-3-hydroxybutyrate (PHB), assuming $142 \mathrm{~J} / \mathrm{g}$ as the melting enthalpy of $100 \%$ crystalline PHB (eqn. (9))

$X_{p}=\frac{\Delta H_{m}}{\Delta H_{m}^{o}}$

\section{Thermogravimetry analysis}

Decomposition temperature of the sample was measured by thermogravimetric analysis. The biopolymer was subjected to a heating rate of $20^{\circ} \mathrm{C} / \mathrm{min}$ from ambient to a final temperature of $500{ }^{\circ} \mathrm{C}$ under nitrogen flow rate of $20 \mathrm{ml} / \mathrm{min}$.

\section{RESULTS AND DISCUSSION}

\section{Growth rate analysis}

The growth behavior of $P$. putida SS9 was observed by determining the optical density at $600 \mathrm{~nm}$ at different time intervals. A linear regression equation was obtained as $y=114.66 x+0.066$ with determinant coefficient, $R^{2}=0.951$ where y is $\mathrm{OD}_{600}$ of bacterial cells and $\mathrm{x}$ is DCW in $\mathrm{g} / \mathrm{l}$ (Results not shown).

\section{Effect of culture pH on DCW and PHA}

Fig. 1 shows the effect of initial culture $\mathrm{pH}$ on DCW and PHA production. A maximum of $72.22 \%$ of PHA content was recorded at $7.0 \mathrm{pH}$. P. putida SS9 produced $61.9 \%$ and $70.83 \%$ of $\mathrm{PHA}$ at a $\mathrm{pH}$ of 6 and 8 respectively which were below the values recorded at $\mathrm{pH} 7$, thus, constituting that the optimum $\mathrm{pH}$ for PHA accumulation was $\mathrm{pH}$ 7.0. These results are in consonance with the results obtained by Wei et al. 2011. Further at pH 9.0, a very low PHA yield of 53.84\% was obtained when compared to yield obtained at all other $\mathrm{pH}$. These outcomes implied that PHA production is susceptible to the cultivation $\mathrm{pH}$. Typically, metabolic processes were extremely sensitive to even slight changes in $\mathrm{pH}$ Hence, appropriate control of $\mathrm{pH}$ is significant and deviation on the either side of the optimum $\mathrm{pH}$ led to fall in PHA accumulation.

\section{Effect of culture temperature on DCW and PHA}

The effect of temperature on DCW and PHA production by $P$. putida SS9 was also evaluated. $P$. putida SS9 was examined at $25,30,35$ and $40{ }^{\circ} \mathrm{C}$. Fig. 2 demonstrates that the optimal temperature for cell growth and PHA production was $30{ }^{\circ} \mathrm{C}$. Maximum DCW of $5.2 \mathrm{~g} / \mathrm{l}$ and PHA production of $3.8 \mathrm{~g} / 1(73.7 \%)$ occurred at $30{ }^{\circ} \mathrm{C}$. The PHA yield was shown to decrease with increasing temperature above $30{ }^{\circ} \mathrm{C}$ because of an increase of the anabolic rate at higher temperatures. Therefore, temperature was also considered as an influential parameter like $\mathrm{pH}$ which affects the metabolic process and growth of microorganism. As a mesophile microorganism from soil environment, the increase in cultivation temperature up to 35 and $40{ }^{\circ} \mathrm{C}$ could lead to significant lower production of biomass (Gomaa, 2014). In addition, it could be concluded from the figure that the increase in temperature contribute to a reduced accumulation of PHA by $P$. putida SS9 as an energy reserve to combat physiological stress. Therefore, the temperature of fermentation process is essentially needed to be maintained at optimum level to attain high accumulation of PHA for industrial production. 


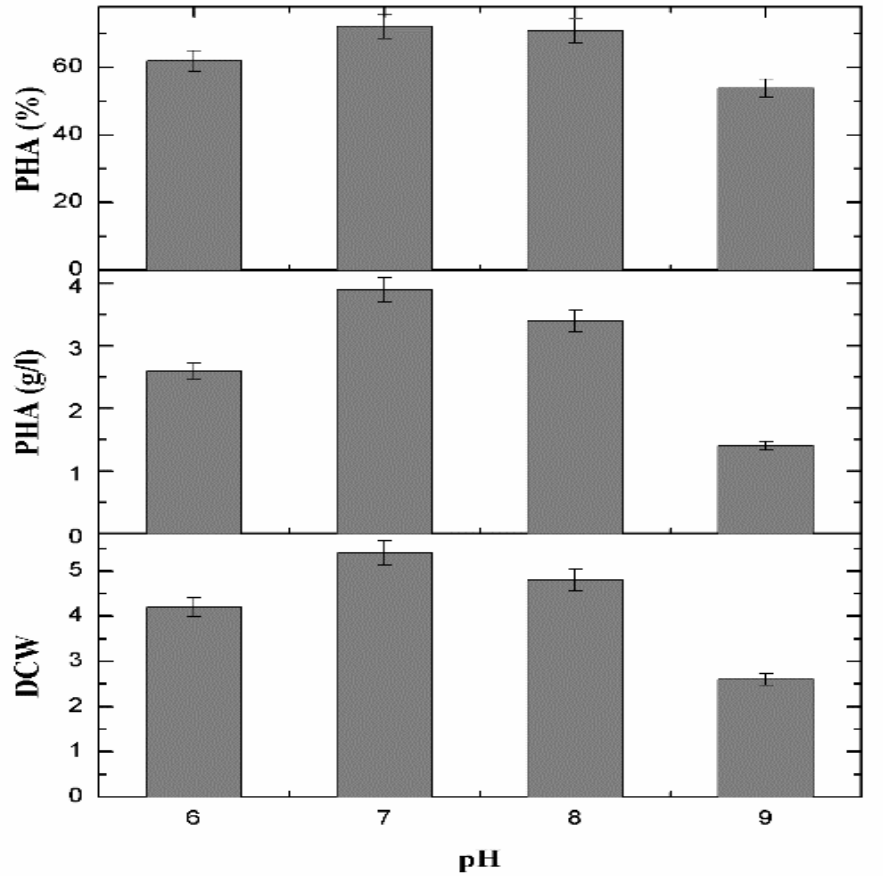

Figure 1 Effect of $\mathrm{pH}$ on growth and PHA production, the error bars represent 95 $\%$ confidence intervals. The data are expressed as means $(n=3)$ with $\mathrm{p}<0.05$ that are not significantly different from each other in the chart.*

*Temperature: Ambient temperature, Nitrogen source concentration: $2 \mathrm{~g} / \mathrm{l}$

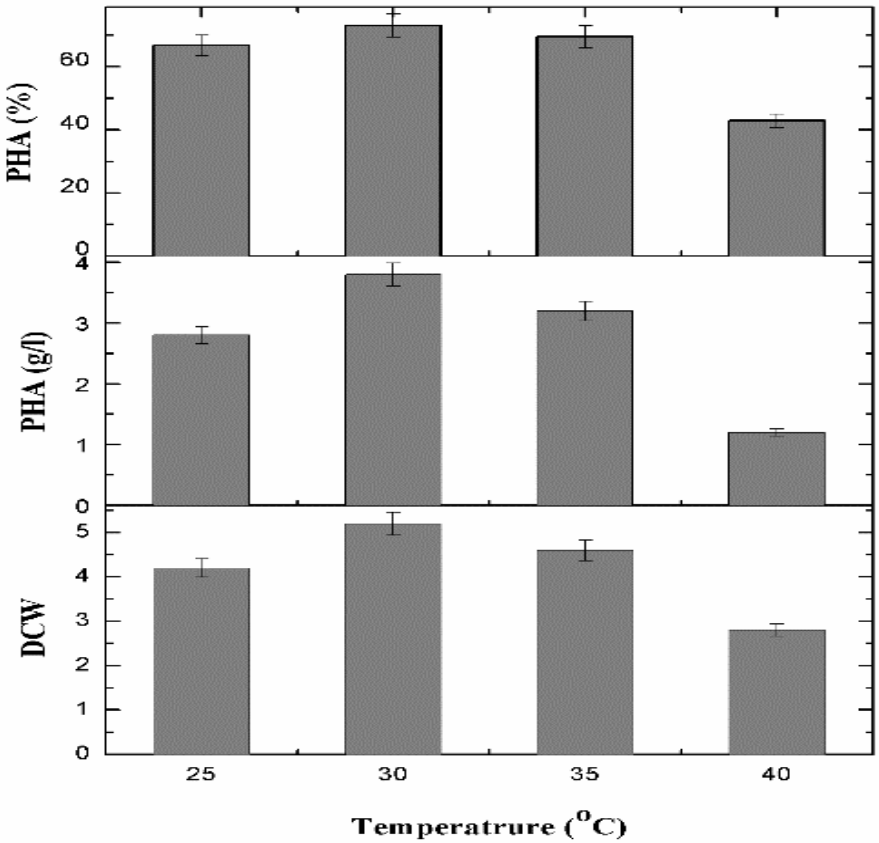

Figure 2 Effect of temperature on growth and PHA production, the error bars represent $95 \%$ confidence intervals. The data are expressed in means $(n=3)$ with $\mathrm{p}<0.05$ that doesn't differ considerably with each other.*

* $p H$ : 7, Nitrogen source concentration: $2 \mathrm{~g} / \mathrm{l}$

\section{Effect of nitrogen source concentration on DCW and PHA}

The effect of nitrogen source concentration is exhibited in the Fig. 3. The bacterial growth has been observed to increase as the concentration of nitrogen source increases and the PHA production has been found to increase as the concentration of nitrogen source decreases. In the absence of nitrogen source, no growth was detected and the cells turned out as bleached. A maximum PHA content of $4.2 \mathrm{~g} / \mathrm{l}$ and minimum biomass concentration of $5.6 \mathrm{~g} / \mathrm{l}$ has been obtained at $0.5 \mathrm{~g} / \mathrm{l}$ nitrogen source concentration. Whereas at the maximum nitrogen source concentration of $2.0 \mathrm{~g} / \mathrm{l}$, the PHA content has been found decreased $(1.1 \mathrm{~g} / \mathrm{l})$ and the biomass concentration has been found increased $(6.3$ $\mathrm{g} / \mathrm{l})$. The present study supports in understanding the culture growth and PHA production under nitrogen starvation. The excess nitrogen concentration facilitates the growth of the organism, whereas, the PHA production found to be reduced by increasing the nitrogen source concentration. Therefore, nitrogen source concentration becomes rate limiting during PHA production using $P$. putida SS9. The results also revealed that $(\mathrm{NH} 4)_{2} \mathrm{SO}_{4}$ had a positive effect on PHA production and the rate limiting $(\mathrm{NH} 4)_{2} \mathrm{SO}_{4}$ concentration of $0.5 \mathrm{~g} / \mathrm{l}$ has been measured as the optimal nitrogen source for producing PHA.

\section{Effect of aeration and agitation on DCW and PHA}

The effect of aeration and agitation on DCW and PHA production is illustrated in the Fig. 4 and 5. The DCW has been found increased as the aeration rate (2.3, $3.6,4.4,5.2$, and $6.6 \mathrm{~g} / \mathrm{l}$ at $0.5,0.75,1.0,1.25$, and $1.5 \mathrm{vvm}$, respectively) increases. However, the DCW declined at high agitation rate $(5.3,4.3,3.5$, and 2.4 at 100, 200, 300, and $400 \mathrm{rpm}$, respectively) (Fig. 4). The maximum DCW value was obtained at lower rpm (100 rpm) whereas the DCW at higher rpm (400 $\mathrm{rpm}$ ) was lowered due to increased shear force and mixing effects. The high shear speed was responsible for high shear stress causing heterogeneous mixing. This poor mixing had greater impact on oxygen transfer and activities of the cell during fermentation. The PHA production was found to be increased as aeration rate increased $(1.38,2.1,3.31,3.39$, and $4.72 \mathrm{~g} / 1$ at $0.5,0.75,1.0,1.25$, and 1.5 vvm, respectively) (Fig. 5). Further, the PHA production decreased as agitation speed increased $(3.98,3.11,2.16$, and $1.4 \mathrm{at} 100,200,300$, and $400 \mathrm{rpm}$, respectively). The PHA yield was escalated by increased aeration rate and decreased agitation rate, deducing the consequences of DCW. Therefore the results demonstrates the common fact that greater the cell growth lead to greater the product yield. Maximum PHA yield of $4.72 \mathrm{~g} / \mathrm{l}$ at highest aeration rate and $3.98 \mathrm{~g} / \mathrm{l}$ at lowest agitation rate was observed during optimization of aeration and agitation. The maximum air flow in the tested aeration limit supports the growth and activity of $P$. putida SS9 and thereby product yield was enhanced. Alternatively, high agitation rate reduced the metabolic production of PHA due to the deformation of cell and its damages. Further, vigorous mixing at high agitation inhibits the nutrient transport and its consumption during cell growth reduces the oxygen transport causing cell growth inhibition. Hence inappropriate agitation rates leads to heterogeneous mixing and shear stress responsible for fragile microorganism damage and reduced PHA production.

\section{Effect of aeration and agitation on $k_{\mathrm{L}}$ a}

The $P$. putida SS9 was cultivated in MSM and CWM in 3L fermenter at aeration rate of $1.5 \mathrm{vvm}$ and agitation rate of $200 \mathrm{rpm}$. The dynamic gassing-out technique was used to determine the $\mathrm{k}_{\mathrm{L}}$ a with experimental graph (Fig. 6). The broth was deoxygenated by stopping the air flow and culture was allowed to consume the available oxygen in the solution which is indicated by the curve downturned when air supply was interrupted. The curve was elevated as air supply is restarted (Fig. 6), indicating the increases in the DO content and change of oxygen content ( $\mathrm{dCo} / \mathrm{dt}$ value) in the fermenter, while the oxygen was still under consumption by cells. A similar curve was obtained during cultivation of $P$. putida SS9 in both MSM and CWM. The period of downturn DO measurement was relatively higher than the period of DO elevation. This signified the oxygen diffusion in the system faster than oxygen consumption time which indicate that the both production medium (MSM and CWM) didn't turn viscous (significantly inhibit oxygen transfer) and more appropriate for PHA production during scale up. Fig. 7(a) and 7(b) indicates that $\mathrm{k}_{\mathrm{L}}$ a value increases considerably on increasing aeration from 0.5 to $1.5 \mathrm{vvm}$ throughout the fermentation. Increasing the aeration rate from 1.0 to $1.5 \mathrm{vvm}$ showed a considerable effect on PHA production from both MSM and CWM. This may be due to increase in microbial population. The highest rates of PHA production were obtained for the highest $k_{L} a$ values. The value of $k_{L} a$ was increased from 14.25 to 16.2 and 15.3 to 16.3 for MSM and CWM respectively on increasing the aeration rate. It is important to highlight that aeration had a positive impact on PHA production and is dependent of agitation. Further, there has been an increase in $\mathrm{k}_{\mathrm{L}}$ a value of about $10 \%$ after 15 hours. It was observed that highest $\mathrm{k}_{\mathrm{L}} \mathrm{a}$ values were attained during increment of aeration for PHA production using CWM on comparison with MSM. The effect of agitation on $\mathrm{k}_{\mathrm{L}} \mathrm{a}$ during PHA production from MSM and CWM were shown in Fig. 7(c \& d). In MSM, maximum $\mathrm{k}_{\mathrm{L}}$ a of $142,147.1,149.8$, and $150.7\left(\mathrm{~h}^{-1}\right)$ was obtained for the agitation rates of $100,200,300$ and $400 \mathrm{rpm}$ respectively, where as in CWM, the maximum $\mathrm{k}_{\mathrm{L}}$ a of $160.4,161.6,162.8$ and 164.5 was obtained for agitation rates of $100,200,300$ and $400 \mathrm{rpm}$ respectively. It can be noticed that the $\mathrm{k}_{\mathrm{L}} \mathrm{a}$ values during PHA production was found to be increased with increased agitation speed in synthetic MSM medium, whereas in CWM, the $\mathrm{k}_{\mathrm{L}}$ a values increased predominantly up to $10 \mathrm{~h}$ and later on decreased drastically on increase in time and agitation as well. This may be due to the submerged culture production is affected by shear stress, shear force and mixing delay time, which is related to agitation rate. The shear forces as a result of intensive agitation decreases the value of $\mathrm{k}_{\mathrm{L}} \mathrm{a}$ and thereby productivity was also affected. These results signify that the $\mathrm{k}_{\mathrm{L}} \mathrm{a}$ was more affected by agitation than aeration especially in CWM. The increase in aeration and agitation rate increased the values of $\mathrm{k}_{\mathrm{L}} \mathrm{a}$, whereas the increase in agitation rate decreased the PHA yield. The study of effect of aeration produced a positive correlation on $\mathrm{k}_{\mathrm{L}} \mathrm{a}$ and $\mathrm{PHA}$ yield whereas it produced a negative correlation with effect of agitation on $\mathrm{k}_{\mathrm{L}} \mathrm{a}$ and PHA yield (Bandaiphet and Prasertsan, (2006); Garcia-Ochoa et al., (2000). In most aerobic process, the biopolymer productivity was found increases with aeration rate and agitation speed. However the negative effect of agitation rate was considerably higher than 
aeration rate. The agitation affects the rate of oxygen transfer higher than aeration in all mechanically agitated reactors (Elibol and Ozer, 2000). The experimental data and results obtained designate that the OTR was strongly dependent on agitation than on aeration. Further, $\mathrm{k}_{\mathrm{L}} \mathrm{a}$ was measured high during appropriate mixing and low during heterogeneous mixing. Therefore, the correlation of $\mathrm{k}_{\mathrm{L}} \mathrm{a}$ and productivity was adequate that manifest the magnitude of mixing had a significant impact on cell growth, oxygen consumption, oxygen transfer during fermentation process.

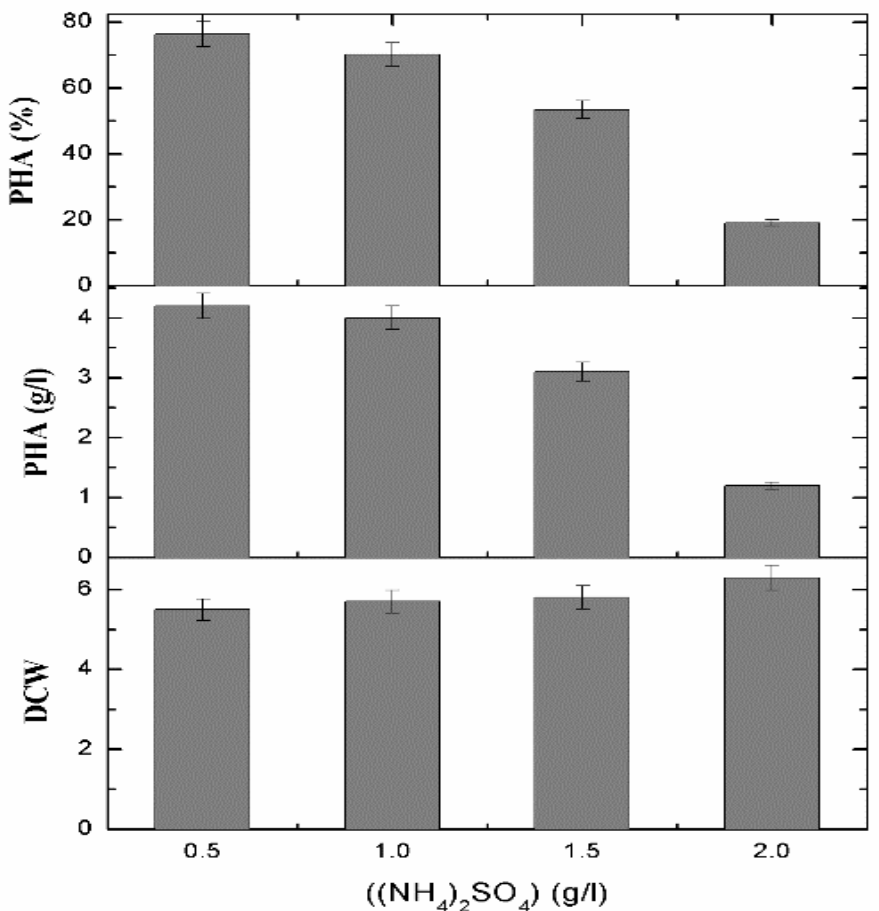

Figuer 3 Effect of nitrogen on growth and PHA production, the error bars represent $95 \%$ confidence intervals. The data are represented in means $(n=3)$ with $\mathrm{p}<0.05$ which are not substantially distinct from each other*

*pH: 7, Temperature: $30^{\circ} \mathrm{C}$

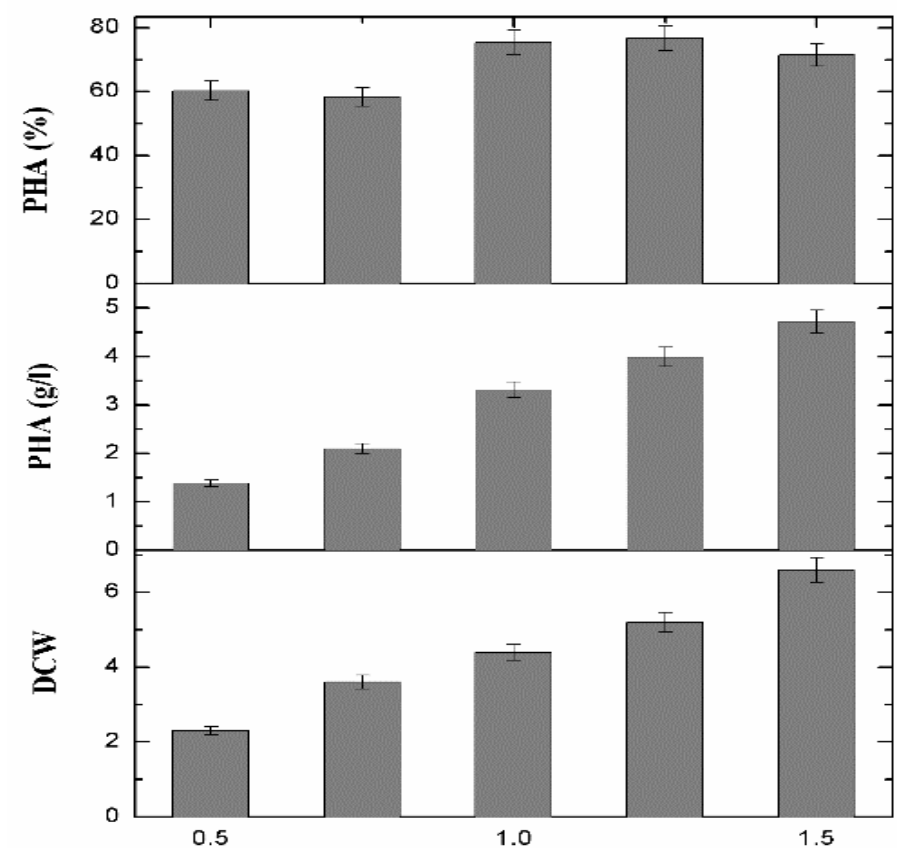

Aeration rate (vvm)

Figure 4 Effect of aeration on DCW and PHA, the error bars represent $95 \%$ confidence intervals. The data are represented in means $(n=3)$ with $p<0.05$ which are not substantially distinct from each other*

${ }^{*} p H: 7$, Temperature: $30^{\circ} \mathrm{C}$, Nitrogen source concentration: $0.5 \mathrm{~g} / \mathrm{l}$, Agitation: $200 \mathrm{rpm}$

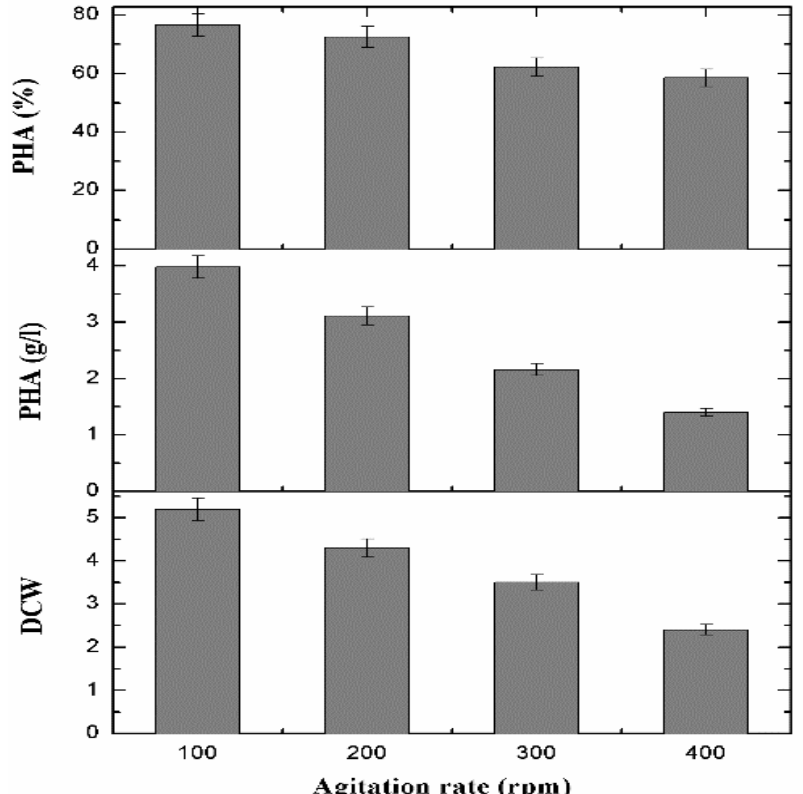

Figure 5 Effect of agitation on DCW and PHA, the error bars represent $95 \%$ confidence intervals. The data are represented in means $(n=3)$ with $p<0.05$ which are not substantially distinct from each other. *

${ }^{*} p H$ : 7, Temperature: $30^{\circ} \mathrm{C}$, Nitrogen source concentration: $0.5 \mathrm{~g} / \mathrm{l}$, Aeration: $1.5 \mathrm{vvm}$

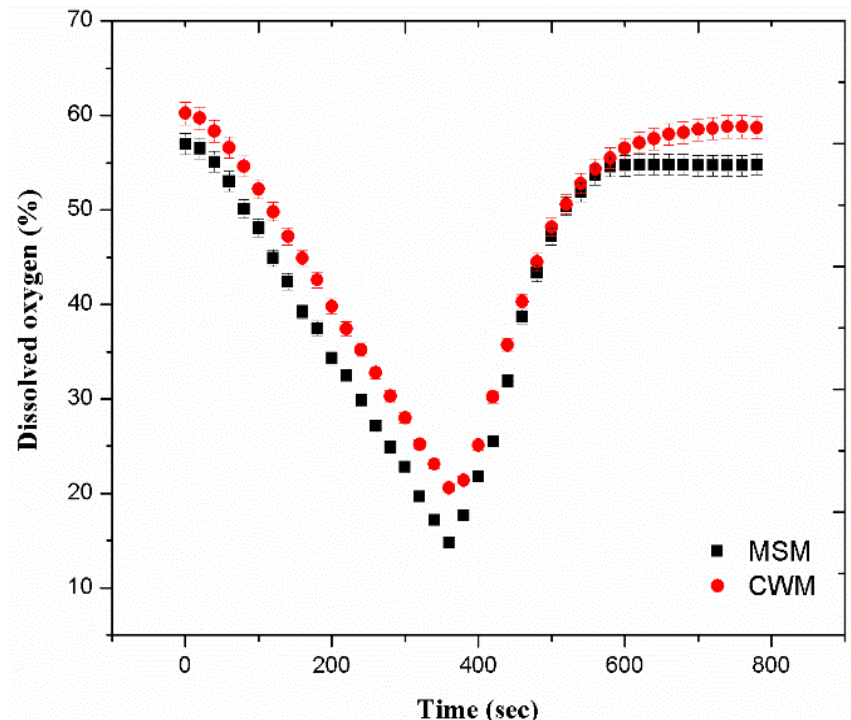

Figure 6 Experimental graph of dynamic gassing out technique of OUR and OTR determination during $P$. putida SS9 cultivation in mineral salts medium (MSM) and cheese whey medium (CWM) at $1.0 \mathrm{vvm}, 200 \mathrm{rpm}$ in $3 \mathrm{~L}$ fermentor, the error bars represent $95 \%$ confidence intervals. The data are represented in means $(n=3)$ with $\mathrm{p}<0.05$ which are not substantially distinct from each other.

\section{PHA production in MSM and CWM under controlled $\mathrm{k}_{\mathrm{L}} \mathrm{a}$}

Production of PHA by $P$. putida SS9 with respect to time in MSM and CWM were shown in Fig. 8 and 9, respectively. From Fig. 8, it can be observed that the DCW and PHA yield was found to be low at initial culture time and later on increased with increase in time. The maximum PHA yield in MSM was observed as $74.6 \%$ after 90 hours with 4.32 g/l PHA accumulation. From Fig. 9 , it can be recognized that the PHA yield was more or less consistent throughout the growth period of $P$. putida SS9. The initial amount of nitrogen and carbon in CWM was estimated using eqn. (3) and (4), respectively. The amount of nitrogen was found to be $858.67 \mathrm{mg} / \mathrm{l}$ in terms of ammonia and the carbon concentration was determined as $9.82 \mathrm{~g} / \mathrm{l}$ in terms of lactose. The maximum PHA yield of $77.77 \%$ was observed in CWM with $5.98 \mathrm{~g} / 1$ PHA accumulation. The PHA production was found to profoundly higher in CWM and found greater than the amount obtained with defined medium (MSM) using $P$. putida SS9. These results suggest that, $P$. putida SS9 utilizes the cheese whey as improved carbon source and provide a maximum yield under controlled and optimal aeration rate, agitation rate, and $\mathrm{k}_{\mathrm{L}} \mathrm{a}$. The yield was compared with several other microorganisms with cheese whey as substrate medium (Table 1). 

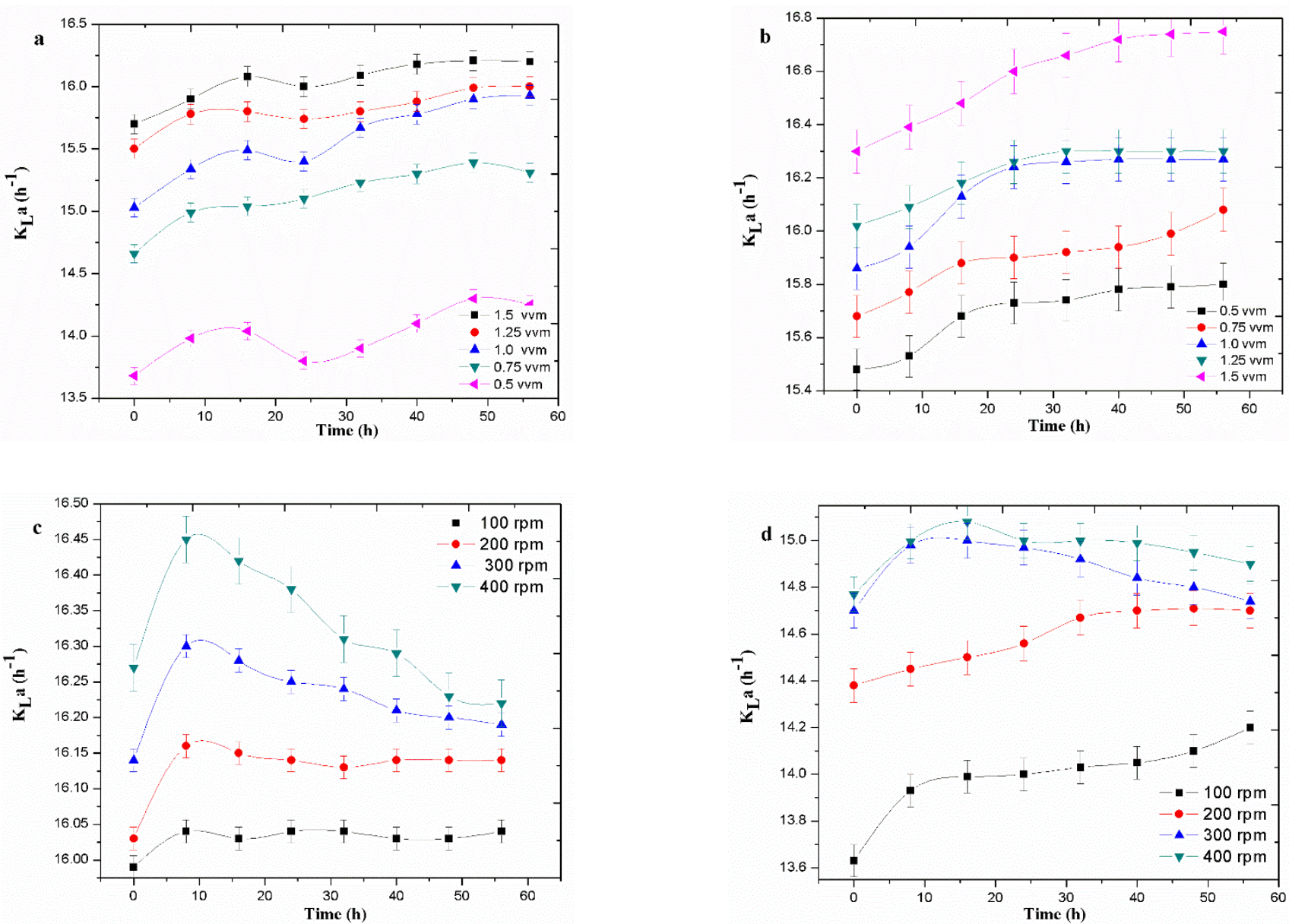

Figure 7 Comparison of effect of aeration and agitation on $\mathrm{k}_{\mathrm{L}} \mathrm{a}$ between mineral salts medium (a \& c) and cheese whey medium (b \& d) during PHA prodution using $P$. putida SS9, the error bars represent $95 \%$ confidence intervals. The data are represented in means $(\mathrm{n}=3)$ with $\mathrm{p}<0.05$ which are not substantially distinct from each other*

${ }^{*} p H$ : 7, Temperature: $30^{\circ} \mathrm{C}$, Nitrogen source concentration: $0.5 \mathrm{~g} / \mathrm{l}$

Table 1 Comparison of PHB content from different bacterial strains

\begin{tabular}{lllll}
\hline Organism & Substrate & PHA Conc. (g/l) & PHA content $(\%)$ & Reference \\
\hline P.putida SS9 & CWM & $\mathbf{5 . 9 8}$ & $\mathbf{7 7 . 7}$ & Present study \\
P.putida SS9 & MSM & $\mathbf{4 . 3 3}$ & $\mathbf{7 4 . 6}$ & Present study \\
Methylobacterium sp. & Cheese whey & 2.07 & - & Koller et al., 2007 \\
Methylobacterium sp. & Cheese whey & 5.9 & 59.6 & Yellore and Desai, 1998 \\
P. hydrogenovora & Cheese whey & 1.3 & 12 & Koller et al., 2007 \\
Hydrogenophaga pseudoflava & Cheese whey & 2.7 & 40 & Koller et al., 2007 \\
Haloferax mediterranei & Cheese whey & 5.5 & 50 & Koller et al., 2007 \\
B. megaterium & Cheese whey & 1.05 & - & Obruca et al., 2011 \\
Thermus thermophilus & Whey based media & 0.57 & 35.6 & Pantazaki et al., 2009 \\
\hline
\end{tabular}

\section{Structural analysis by FTIR}

The IR spectra of the extracted PHA were compared with that of the standard polyhydroxy-3-butyric acid. The results of FTIR spectroscopy of standard PHB PHB from MSM and CWM are shown in Fig. 10. From the IR spectra, absorption bands of PHA from MSM and CWM were observed similar peaks with the standard spectra. The groups $\mathrm{C}=\mathrm{O}$ was entrusted as functional groups of the biopolymer (PHB). The polymer extracted showed the intense absorption characteristic for ester carbonyl $(\mathrm{C}=\mathrm{O})$ stretching groups at $1722 \mathrm{~cm}^{-1}$ in comparison with the standard polyhydroxybutyrate. The absorption band at $2956.97 \mathrm{~cm}^{-1}$ represents $-\mathrm{CH}_{2}$ groups, followed by a peak at $1722 \mathrm{~cm}^{-1}$ that has been recorded as a PHB marker band which shows the presence of $-\mathrm{C}=\mathrm{O}$ and then a distinct peak at $1280.50 \mathrm{~cm}^{-1}$ that indicates $-\mathrm{C}-\mathrm{O}$ in stretched form which indicates that the polyesters are all of 3-hydroxy alkanoates. 


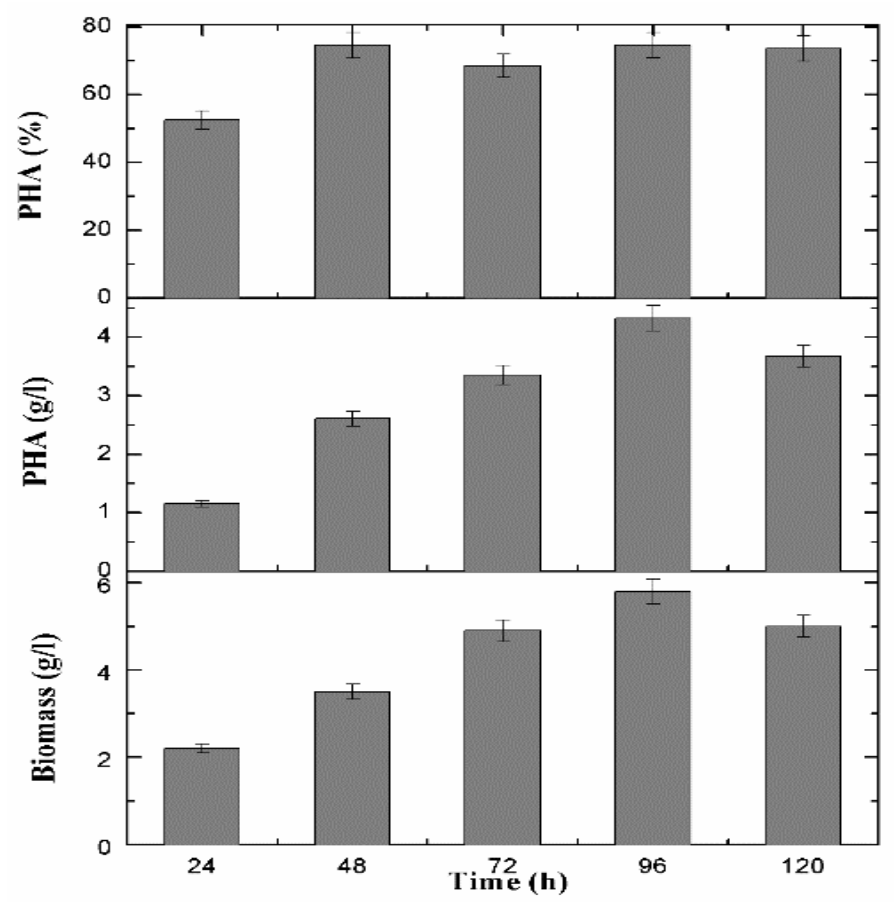

Figure 8 PHA production on MSM using $P$. putida SS9 under optimized condition, the error bars represent $95 \%$ confidence intervals. The data are represented in means $(n=3)$ with $p<0.05$ which are not substantially distinct from each other

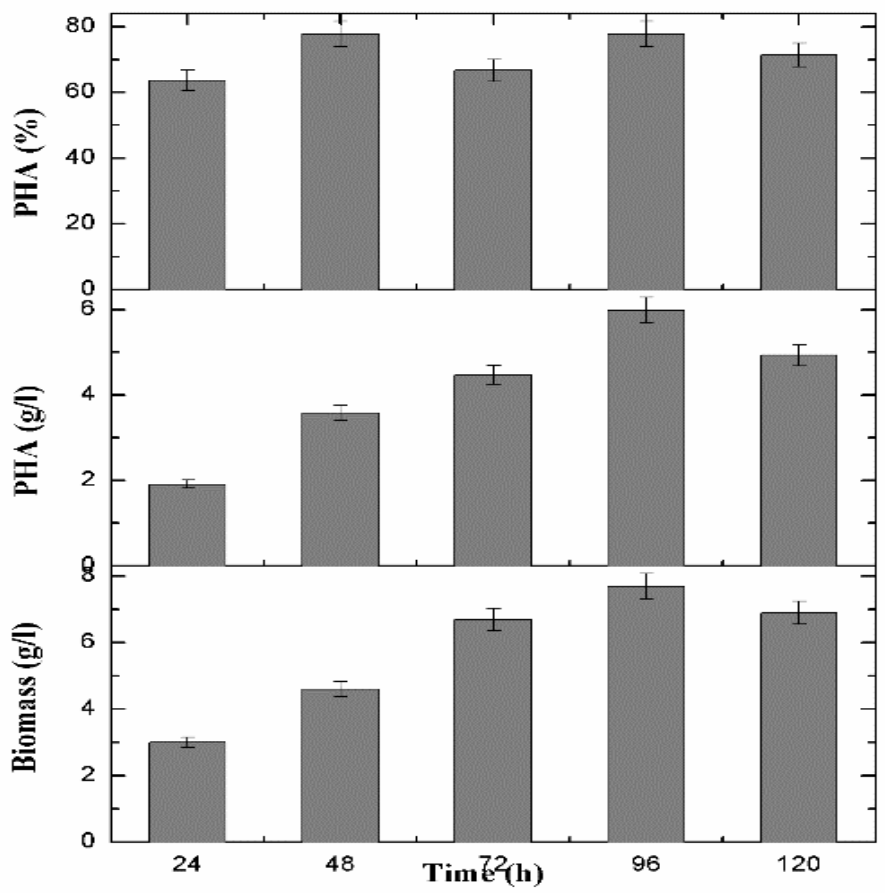

Figure 9 PHA production on CWM using P.putida SS9, the error bars represent

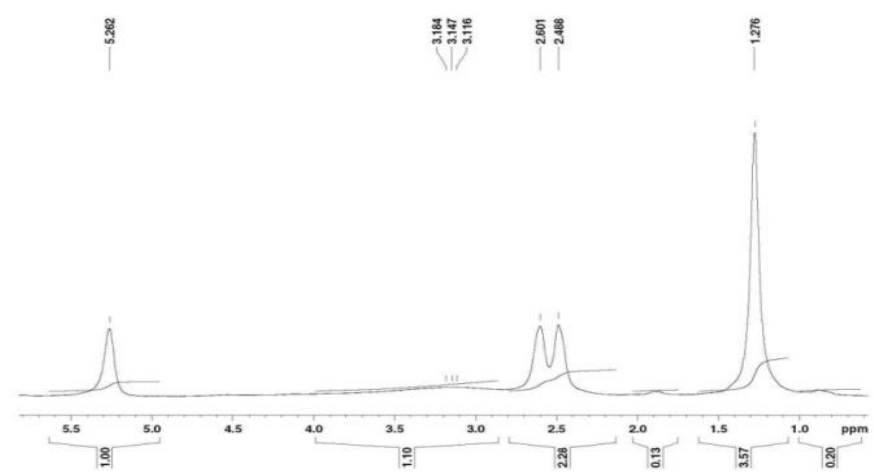

Figure $11{ }^{1} \mathrm{H}$ NMR spectrum of PHB from MSM
$95 \%$ confidence intervals. The data are represented in means $(n=3)$ with $p<0.05$ which are not substantially distinct from each other

All the spectra exhibit the evidence of methyl and methylene group in the range $3000-2800 \mathrm{~cm}^{-1}$. Asymmetric $\mathrm{CH}_{2}$ groups of the lateral monomeric chains are represented by the stretching vibration at $2925.48 \mathrm{~cm}^{-1}$. The absorption peak at $2855.99 \mathrm{~cm}^{-1}$ is attributed to symmetrical $\mathrm{CH}_{3}$ and magnitude of the band in the sample is sharper suggesting that the polymer is crystalline. The peaks at 1453 and $1379 \mathrm{~cm}^{-1}$ attribute to asymmetric and symmetric stretching of the methyl groups. The peaks at 1280, 1227 and $1181 \mathrm{~cm}-1$ in FTIR spectra correspond to aliphatic ester group vibrations. Similar identical FTIR spectral bands were reported by Kovalcik et al., (2017). The absorption peaks in the region of 1754.90 and $2958.26 \mathrm{~cm}^{-1}$ were found to be the same as in the standard PHB which authenticate the presence of PHB in the extracted PHA sample.

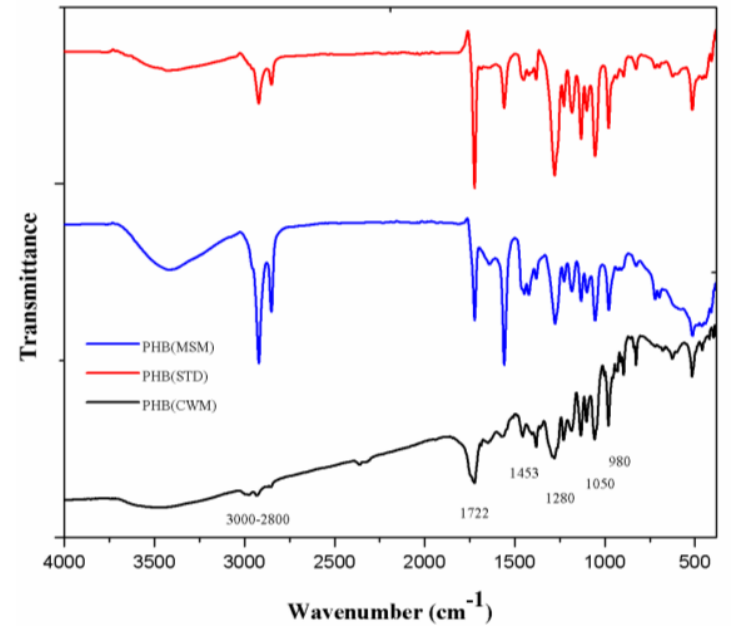

Figure 10 IR spectra of PHB

\section{Structural elucidation by NMR}

PHB structural composition was analyzed using NMR spectroscopy. ${ }^{1} \mathrm{H}$ NMR spectra attained for PHB samples extracted from MSM and CWM was shown in Fig. 11 and 12 respectively. ${ }^{1} \mathrm{H}$ NMR spectrum for PHB from MSM illustrates peak at 2.601 to 2.488 and $5.262 \mathrm{ppm}$ that corresponds to methylene and methine protons of $\alpha, \beta$ carbon respectively. The peak at $1.276 \mathrm{ppm}$ is attributed to methylene protons in side chain. Peak at $0.890 \mathrm{ppm}$ is assigned to terminal methyl proton of side chain. ${ }^{1} \mathrm{H}$ NMR spectrum for PHB from CWM showed multiple peaks at 2.629 to $2.452 \mathrm{ppm}$ and 5.277 to $5.238 \mathrm{ppm}$ are ascribed to methylene and methane protons respectively. ${ }^{13} \mathrm{C}$ NMR spectra obtained for PHB samples extracted from MSM and CWM medium was shown in Fig. 13 and 14 respectively. The observed peaks from ${ }^{13} \mathrm{C}$ NMR spectra for PHB sample from MSM and CWM coincide with the different kinds of carbon atoms in the PHB structure such as carbonyl $(\mathrm{C}=\mathrm{O})$, methane $(\mathrm{CH})$, methylene $\left(\mathrm{CH}_{2}\right)$, and methyl $\left(\mathrm{CH}_{3}\right)$ groups.
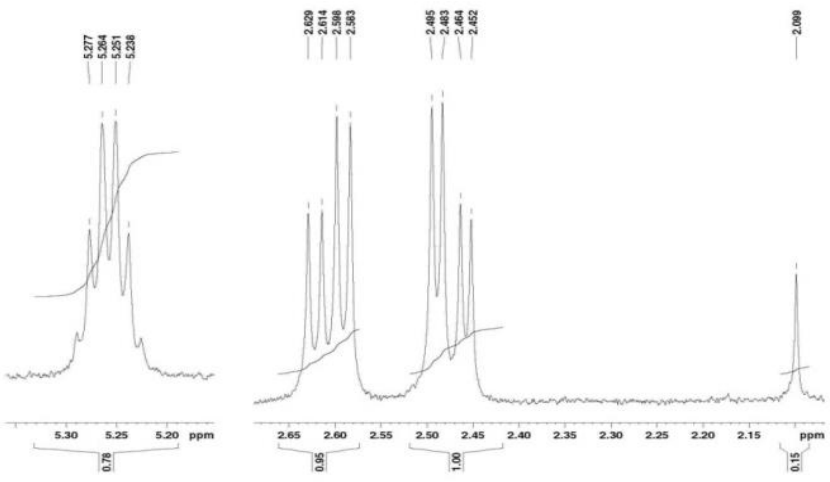

Figure $12{ }^{1} \mathrm{H}$ NMR spectrum of PHB from CWM 
The chemical shift signals of the PHB extracted from MSM and CWM are compared and exhibited in Table 2. The results were matching with those established by Oliveira et al., (2007). The chemical shift signals of spectra obtained from ${ }^{1} \mathrm{H}$ NMR and ${ }^{13} \mathrm{C}$ NMR for both the samples obtained from defined

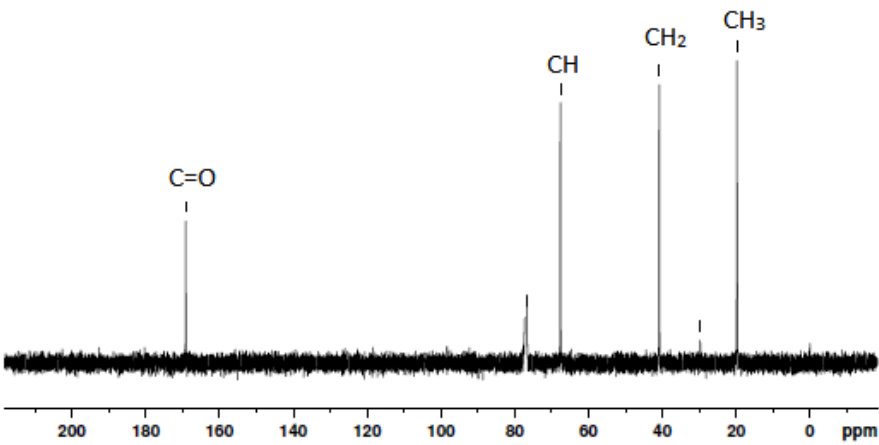

Figure $13{ }^{13} \mathrm{C}$ NMR spectrum of PHB from MSM

Table $2{ }^{13} \mathrm{C}$ NMR chemical shift signal of PHB extracted from MSM and CWM

\begin{tabular}{lll}
\hline \multirow{2}{*}{ Carbon group } & Chemical shift (ppm) & \\
\cline { 2 - 3 } & PHB from MSM & PHB from CWM \\
\hline $\begin{array}{l}\mathrm{C}=\mathrm{O} \\
\text { (Carbonyl) }\end{array}$ & 169.151 & 169.155 \\
$\mathrm{CH}$ & 67.61 & 67.62 \\
$\begin{array}{l}\text { (Methine) } \\
\mathrm{CH}\end{array}$ & & \\
(Methylene) & 40.79 & 40.79 \\
$\mathrm{CH}_{3}$ (Methyl) & 19.75 & 19.76 \\
\hline
\end{tabular}

Table 3 Thermal properties of PHB using DSC

\begin{tabular}{lcccc}
\hline \multirow{2}{*}{ Sample } & $\begin{array}{c}\text { Glass transition } \\
\text { temperature }\left(\boldsymbol{T}_{\boldsymbol{g}}\right)\end{array}$ & $\begin{array}{c}\text { Melting temperature } \\
\left(\boldsymbol{T}_{\boldsymbol{m}}\right)\end{array}$ & $\begin{array}{c}\text { Endothermic melting } \\
\text { enthalpy }\left(\boldsymbol{\Delta H}_{\boldsymbol{m}}\right)\end{array}$ & $\begin{array}{c}\text { Polymer crystallinity } \\
\left(\boldsymbol{X}_{\boldsymbol{p}}\right)\end{array}$ \\
\cline { 2 - 5 } & $\left({ }^{\circ} \mathrm{C}\right)$ & $\left({ }^{\circ} \mathrm{C}\right)$ & $\mathrm{Jg}^{-1}$ & $\%$ \\
\hline PHB from MSM & 1.81 & 176.2 & 91.4 & 64.3 \\
PHB from CWM & 1.01 & 171.1 & 85.9 & 60.5 \\
\hline
\end{tabular}

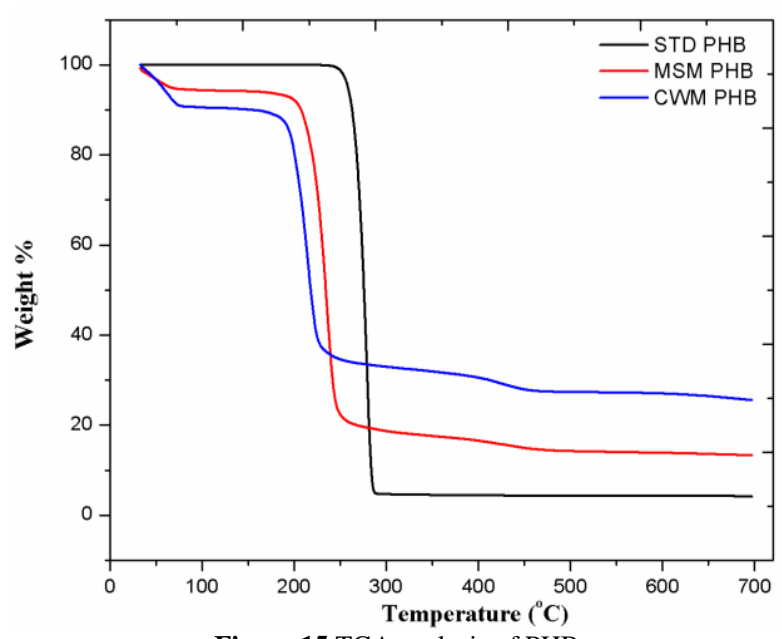

Figure 15 TGA analysis of PHB

\section{CONCLUSION}

The present study investigated the potential of $P$. putida SS9 to produce PHB using cheese whey as substrate under controlled aeration, agitation, and $\mathrm{k}_{\mathrm{L}} \mathrm{a}$. Cheese whey became economical in PHB production as it is produced in surplus in dairy industry. Nitrogen starvation stimulates the organism to expose the intracellular PHB out of the cell. The quality of biopolymer is highly influenced by the method of extraction. Polar solvents, especially chlorinated solvents such as chloroform were found to give high quality PHB and high extraction yield. The effect of agitation on PHB production represents inappropriate agitation rates leads to heterogeneous mixing and shear stress responsible for fragile microorganism damage and reduced PHA production. Similarly, the study of medium as well as $\mathrm{CWM}$ were found to coincide with each other corresponding to the structure [- $\left.\mathrm{O}-\mathrm{CH}-\left(\mathrm{CH}_{3}\right)-\left(\mathrm{CH}_{2}\right)-(\mathrm{C}=\mathrm{O})-\right]_{n}$ of PHB. The results obtained were similar to that of Arumugam et al., (2018). Thus, it can be concluded from the above results that the polymer obtained is PHB

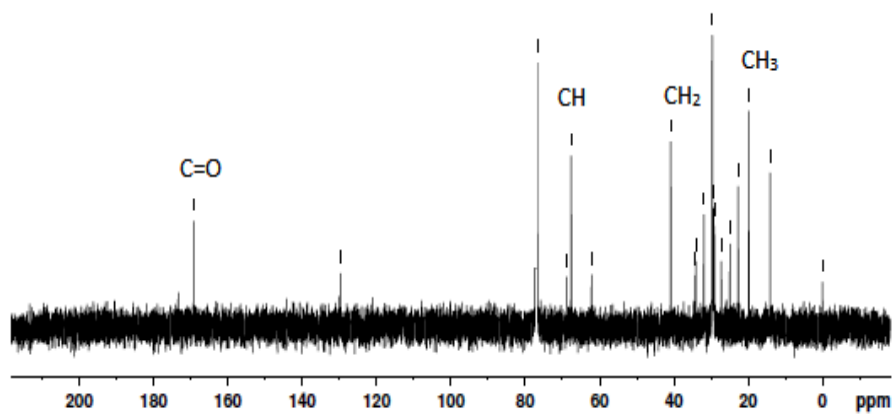

Figure $14{ }^{13} \mathrm{C}$ NMR spectrum of PHB from CWM

\section{Thermal analysis}

he thermal properties of PHB samples extracted from MSM and CWM were examined by DSC and TGA. The degree of crystallinity $\left(X_{p}\right)$ of polymer was calculated from the melting enthalpy. Table 3 displays the results of DSC. The thermal properties of PHB such as $T_{g}, T_{m}$ and $\Delta H_{m}$ acquired from both the sources were found to be low, which implies that the PHB can be used to blend with other biopolymers or raw materials during bioplastic production processes. Thermogravimetric analysis was conducted for PHB produced from MSM and CWM to analyze the degrading temperature and further compared with standard. The obtained results are presented in Fig. 15. From the result, it is found that, the degrading temperature for standard PHB (B), PHB from MSM (A) and PHB from CWM (C) were found to be 287,256 and $261^{\circ} \mathrm{C}$ respectively. This shows that, the PHB obtained were found to degrade continuously up to $450{ }^{\circ} \mathrm{C}$ and hence need further purification and can be blended with other polymeric material for the bioplastic production. 
AVÉROUS, L., \& POLLET, E. (2012). Biodegradable polymers. In Environmental silicate nano-biocomposites (pp. 13-39). Springer, London. https://doi.org/10.1007/978-1-4471-4108-2 2.

BAJAJ, I. B., \& SINGHAL, R. S. (2010). Effect of aeration and agitation on synthesis of poly ( $\gamma$-glutamic acid) in batch cultures of Bacillus licheniformis NCIM 2324. Biotechnology and Bioprocess Engineering, 15(4), 635-640. https://doi.org/10.1007/s12257-009-0059-2.

BANDAIPHET, C., \& PRASERTSAN, P. (2006). Effect of aeration and agitation rates and scale-up on oxygen transfer coefficient, $\mathrm{kLa}$ in exopolysaccharide production from Enterobacter cloacae WD7. Carbohydrate Polymers, 66(2), 216-228. https://doi.org/10.1016/j.carbpol.2006.03.004.

BERTRAND, J. L., RAMSAY, B. A., RAMSAY, J. A., \& CHAVARIE, C. (1990). Biosynthesis of poly- $\beta$-hydroxyalkanoates from pentoses by Pseudomonas pseudoflava. Applied and environmental microbiology, 56(10), 3133-3138. http://aem.asm.org/content/56/10/3133.short.

BHUWAL, A. K., SINGH, G., AGGARWAL, N. K., GOYAL, V., \& YADAV, A. (2013). Isolation and screening of polyhydroxyalkanoates producing bacteria from pulp, paper, and cardboard industry wastes. International journal of biomaterials, 2013. http://dx.doi.org/10.1155/2013/752821.

ELIBOL, M., \& OZER, D. (2000). Influence of oxygen transfer on lipase production by Rhizopus arrhizus. Process Biochemistry, 36(4), 325-329. https://doi.org/10.1016/S0032-9592(00)00226-0.

EUGENE, W. R., RODGER, B. B., ANDREW, D. E., \& LENORE, S. C. (2012).

Standard methods for the examination of water and wastewater. American Public Health Association, American Water Works Association, Water Environment Federation, 22nd edn. Washington DC, USA Google Scholar.

GARCÍA-OCHOA, F., CASTRO, E. G., \& SANTOS, V. E. (2000). Oxygen transfer and uptake rates during xanthan gum production. Enzyme and microbial technology, 27(9), 680-690. https://doi.org/10.1016/S0141-0229(00)00272-6.

GUMEL, A. M., ANNUAR, M. S. M., \& HEIDELBERG, T. (2014). Growth kinetics, effect of carbon substrate in biosynthesis of mcl-PHA by Pseudomonas putida Bet001. Brazilian Journal of Microbiology, 45(2), 427-438. http://dx.doi.org/10.1590/S1517-83822014000200009.

KEDIA, G., PASSANHA, P., DINSDALE, R. M., GUWY, A. J., \& ESTEVES S. R. (2014). Evaluation of feeding regimes to enhance PHA production using acetic and butyric acids by a pure culture of Cupriavidus necator. Biotechnology and bioprocess engineering, 19(6), 989-995. https://doi.org/10.1007/s12257. 014-0144-z.

KHANDPUR, P., JABEEN, E. T., ROHINI, K. V. L., \& VARAPRASAD, Y. (2012). Study on production, extraction and analysis of polyhydroxyalkanoate (PHA) from bacterial isolates. IOSR J Pharm Biol Sci IOSRJBPS, 1, 31-38. https://doi.org/10.9790/3008-0113138.

KITAMURA, S., \& DOI, Y. (1994). Staining method of poly (3-hydroxyalkanoic acids) producing bacteria by Nile blue. Biotechnology techniques, 8(5), 345-350. https://doi.org/10.1007/BF02428979.

KOLLER, M., HESSE, P., BONA, R., KUTSCHERA, C., ATliĆ, A., \& BRAUNEGG, G. (2007). Potential of various archae-and eubacterial strains as industrial polyhydroxyalkanoate producers from whey. Macromolecular bioscience, 7(2), 218-226. https://doi.org/10.1002/mabi.200600211.

KOLLER, M., SALERNO, A., MUHR, A., REITERER, A., CHIELLINI, E. CASELLA, S \& BRAUNEGG, G. (2012). Whey lactose as a raw material for microbial production of biodegradable polyesters. In Polyester. InTech https://doi.org/10.5772/48737.

KOVALCIK, A., MEIXNER, K., MIHALIC, M., ZEILINGER, W., FRITZ, I., FUCHS, W., \& DROSG, B. (2017). Characterization of polyhydroxyalkanoates produced by Synechocystis salina from digestate supernatant. International journal of biological macromolecules, 102, 497-504. https://doi.org/10.1016/j.ijbiomac.2017.04.054.

KUMAR, H., KUMAR, N., SETH, R., \& GOYAL, A. (2014). Chemical and immunological quality of goat colostrum: effect of breed and milking frequency. Indian Journal of Dairy Science, 67(6), 482-486. https://doi.org/10.1.1.904.8126.

KUMAR, M. S., MUDLIAR, S. N., REDDY, K. M. K., \& CHAKRABARTI, T. (2004). Production of biodegradable plastics from activated sludge generated from a food processing industrial wastewater treatment plant. Bioresource technology, 95(3), 327-330. https://doi.org/10.1016/j.biortech.2004.02.019. LÓPEZ, J. A., NARANJO, J. M., HIGUITA, J. C., CUBITTO, M. A., CARDONA, C. A., \& VILLAR, M. A. (2012). Biosynthesis of PHB from a new isolated Bacillus megaterium strain: outlook on future developments with endospore forming bacteria. Biotechnology and bioprocess engineering, 17(2), 250-258. https://doi.org/10.1007/s12257-011-0448-1.

MACWAN, S. R., DABHI, B. K., PARMAR, S. C., \& APARNATHI, K. D (2016). Whey and its Utilization. Int. J. Curr. Microbiol. App. Sci, 5(8), 134-155. http://dx.doi.org/10.20546/ijcmas.2016.508.016.

MOUTAFCHIEVA, D., POPOVA, D., DIMITROVA, M., \& TCHAOUSHEV, S. (2013). Experimental determination of the volumetric mass transfer coefficient. Journal of Chemical Technology and Metallurgy, 48(4), 351-356.

NAIR, S. S., REDDY, H., \& GANJEWALA, D. (2008). Screening and characterization of biopolymers polyhydroxybutyrate producing bacteria. Advance Biotech, 7(4), 13-7.
NATH, A., DIXIT, M., BANDIYA, A., CHAVDA, S., \& DESAI, A. J. (2008). Enhanced PHB production and scale up studies using cheese whey in fed batch culture of Methylobacterium sp. ZP24. Bioresource technology, 99(13), 57495755. https://doi.org/10.1016/j.biortech.2007.10.017.

NIGAM, S., RAI, M. P., \& SHARMA, R. (2011). Effect of nitrogen on growth and lipid content of Chlorella pyrenoidosa. Am J Biochem Biotechnol, 7(3), 124 129. https://doi.org/10.3844/ajbbsp.2011.124.129.

OBRUCA, S., MAROVA, I., MELUSOVA, S., \& MRAVCOVA, L. (2011) Production of polyhydroxyalkanoates from cheese whey employing Bacillus megaterium CCM 2037. Annals of microbiology,61(4), 947-953. https://doi.org/10.1007/s13213-011-0218-5.

OLIVEIRA, F. C., DIAS, M. L., CASTILHO, L. R., \& FREIRE, D. M. (2007). Characterization of poly (3-hydroxybutyrate) produced by Cupriavidus necator in solid-state fermentation. Bioresource technology, 98(3), 633-638. https://doi.org/10.1016/j.biortech.2006.02.022.

PANTAZAKI, A. A., PAPANEOPHYTOU, C. P., PRITSA, A. G., LIAKOPOULOU-KYRIAKIDES, M., \& KYRIAKIDIS, D. A. (2009). Production of polyhydroxyalkanoates from whey by Thermus thermophilus HB8. Process Biochemistry, 44(8), https://doi.org/10.1016/j.procbio.2009.04.002.

SAMBROOK, J., RUSSELL, D.W. 2001. Molecular Cloning: A Laboratory Manual. Cold Spring Harbor Laboratory Press. http://dx.doi.org/10.1002/jobm.3620300824.

SINGH, P., \& PARMAR, N. (2011). Isolation and characterization of two novel polyhydroxybutyrate (PHB)-producing bacteria. African journal of biotechnology, 10(24), 4907-4919. https://doi.org/10.5897/AJB10.1737.

SISO, M. G. (1996). The biotechnological utilization of cheese whey: a review. Bioresource Technology,57(1), 1-11. https://doi.org/10.1016/0960 8524(96)00036-3

TANAMOOL, V., IMAI, T., DANVIRUTAI, P., \& KAEWKANNETRA, P. (2013). An alternative approach to the fermentation of sweet sorghum juice into biopolymer of poly- $\beta$-hydroxyalkanoates (PHAs) by newly isolated, Bacillus aryabhattai PKV01. Biotechnology and bioprocess engineeri7ng, 18(1), 65-74. https://doi.org/10.1007/s12257-012-0315-8.

TRIBE, L. A., BRIENS, C. L., \& MARGARITIS, A. (1995). Determination of the volumetric mass transfer coefficient ( $\mathrm{kLa}$ ) using the dynamic "gas out-gas in" method: analysis of errors caused by dissolved oxygen probes. Biotechnology and bioengineering, 46(4), 388-392. https://doi.org/10.1002/bit.260460412.

WEI, Y. H., CHEN, W. C., HUANG, C. K., WU, H. S., SUN, Y. M., LO, C. W., \& JANARTHANAN, O. M. (2011). Screening and evaluation of polyhydroxybutyrate-producing strains from indigenous isolate Cupriavidus taiwanensis strains. International journal of molecular sciences, 12(1), 252-265. https://doi.org/10.3390/ijms12010252.

YELLORE, V., \& DESAI, A. (1998). Production of poly-3-hydroxybutyrate from lactose and whey by Methylobacterium sp. ZP24. Letters in applied microbiology, 26(6), 391-394. $\quad$ https://doi.org/10.1046/j.1472-

765X.1998.00362.X 